\title{
Arene-Immobilized Ru(II)/TsDPEN Complexes: Synthesis and Applications to the Asymmetric Transfer Hydrogenation of
}

\section{Ketones}

\author{
Simon Doherty, ${ }^{*[a]}$ Julian G. Knight, ${ }^{*[a]}$ Hind Alshaikh, ${ }^{[b]}$ James Wilson, ${ }^{[a]}$ Paul G. Waddell, ${ }^{[a]}$ Corinne \\ Wills $^{[a]}$ and Casey M. Dixon ${ }^{[a]}$
}

[a] Dr. S. Doherty, Dr. J. G. Knight, J. Wilson, Dr. P. G. Waddell, Dr. C. Wills and Dr C. M. Dixon

Newcastle University Centre for Catalysis (NUCAT)

School of Chemistry, Bedson Building

Newcastle University

Newcastle upon Tyne

NE1 7RU, UK

E-mail: simon.doherty@ncl.ac.uk; https://www.ncl.ac.uk/nes/staff/profile/simondoherty.html\#background

[b] Dr. H. Alshaikh

Department of Chemistry

King Abdulaziz University,

Jeddah, Saudi Arabia

Supporting information for this article is given via a link at the end of the document.

\begin{abstract}
The Noyori-lkariya (arene)Ru(II)/TsDPEN precatalyst has been anchored to amorphous silica and DAVISIL through the $\eta^{6}$ coordinated arene ligand via a straightforward synthesis and the derived systems, (arene)Ru(II)/TsDPEN@silica and (arene)Ru(II)/TsDPEN@DAVISIL, form highly efficient catalysts for the asymmetric transfer hydrogenation of a range of electron-rich and electron-poor aromatic ketones, giving good conversion and excellent ee's under mild reaction conditions. Moreover, catalyst generated in situ immediately prior to addition of substrate and hydrogen donor, by reaction of silica-supported [(arene) $\left.\mathrm{RuCl}_{2}\right]_{2}$ with $(S, S)$-TsDPEN, was as efficient as that generated from its preformed counterpart [(arene)Ru\{(S,S)-TsDPEN\}CI]@silica. Gratifyingly, the initial TOFs (up to $1085 \mathrm{~h}^{-1}$ ) and ee's (96-97\%) obtained with these catalysts either rivalled or outperformed those previously reported for catalysts supported by either silica or polymer immobilized through one of the nitrogen atoms of TsDPEN. While the high ee's were also maintained during recycle studies, the conversion dropped steadily over the first three runs due to gradual leaching of the ruthenium.
\end{abstract}

\section{Introduction}

The asymmetric hydrogenation of ketones to alcohols is a pivotal transformation in organic synthesis which is widely used in the production of intermediates and pharmaceuticals. ${ }^{[1]}$ The Noyori arene-Ru(II)/TsDPEN system is among the most versatile and efficient catalysts for asymmetric transfer hydrogenation (ATH), ${ }^{[2]}$ using either an azeotropic mixture of formic acid and triethylamine or propan-2-ol as the hydrogen source, as well as asymmetric hydrogenation $(\mathrm{AH})^{[3]}$ and as such numerous modifications have been reported. ${ }^{[4]}$ Although the Noyori-lkariya catalyst is highly efficient and has been successfully applied in synthetic methodology, ${ }^{[5]}$ the catalyst can be quite costly due to the high catalyst loadings that are often required (0.5-1.0 mol-\%) coupled with the expense of the precious metal and a chiral ligand. As such there has been considerable interest in exploring strategies to immobilize this system onto a solid support to facilitate catalyst separation, recovery and reuse as well as improve product purification and enable integration into a continuous flow process for scale up, all of which will ultimately reduce operating costs. One of the most popular approaches to immobilize these systems has been covalent attachment of a nitrogen-modified TsDPEN to an amorphous or mesoporous silica, while retaining the essential key feature of an 'active $\mathrm{N}-\mathrm{H}^{\text {'. }}{ }^{[6]}$ In addition, while TsDPEN grafted by covalent attachment of nitrogen to polystyrene ${ }^{[7]}$ and $\mathrm{PEG}^{\left[{ }^{[8]}\right.}$ have both been used to immobilize these catalysts with varying levels of success, Xiao developed an alternative approach to immobilizing TsDPEN by attachment to poly(ethylene glycol) via both of its phenyl rings; the corresponding Noyori-Ikariya catalyst is among the most efficient to be reported with fast reaction rates, excellent ee's and outstanding reusability. ${ }^{[9]}$ Other methods used to immobilize (arene) Ru(II)/TsDPEN and facilitate its recovery and reuse include modification of TsDPEN with an imidazolium ${ }^{[10]}$ or phosphonium ${ }^{[11]}$ group for use in ionic liquids and water, respectively, and incorporation of the diamine into a Fréchet-type core-functionalized dendrimer. ${ }^{[12]}$ In more recent developments, (arene)Ru(II)/TsDPEN has been anchored to a support which also incorporates a palladium-based catalyst for cross-coupling and the resulting switchable bifunctional system used as a catalyst for enantioselective cascade reaction sequences. ${ }^{[13]}$

In contrast to the myriad of examples of solid-supported Noyori-lkariya-type catalysts immobilized through the TsDPEN ligand, there appears to be only a single report of immobilization through the $\pi$-arene ring. ${ }^{[14]}$ This system was prepared by polymerization of methacrylate side chain-modified [(arene) $\left.\mathrm{RuCl}_{2}\right]_{2}$ with ethyleneglycol dimethacrylate and the resulting polymers combined with TsDPEN to form an efficient catalyst for the ATH of ketones. However, to the best of our knowledge there are no reports of silica-supported precatalysts tethered via the $\eta^{6}$-coordinated arene, which is somewhat surprising considering there are numerous advantages associated with the use an ordered mesoporous silica as a support for anchoring chiral transition metal catalysts; these include control of surface area and pore volume, tunable pore dimensions, potential for functionalization and good thermal and mechanical integrity. ${ }^{[15]}$ Thus, our interest in developing such an 
arene-anchored catalyst is four-fold, firstly, the straightforward and versatile synthesis of a range of functionalized 1,4cyclohexadienes via cycloaddition would lend itself to catalyst modification and diversification, secondly, a library of catalysts could be generated either before or after silanization by introduction of a suitable chiral diamine or amino alcohol, thirdly, anchoring the catalyst to the support via the arene ring avoids modification of the basic nitrogen atom of Ts-DPEN which has been reported to reduce catalyst activity and enantioselectivity and, finally, arene ruthenium complexes have also been used in a host of other transformations including; 1,4-additions to conjugated enones, ${ }^{[16]}$ hydrosilylations, ${ }^{[17]}$ arene hydrogenation, ${ }^{[18]}$ oxidation of alcohols, ${ }^{[19]}$ Diels-Alder cycloadditions, ${ }^{[20]}$ cyclopropanation, ${ }^{[21]}$ the hydrocarboxylation of alkynes $^{[22]}$ and ring-opening and ring-closing metathesis ${ }^{[23]}$ and as such this strategy may well have much broader applications. Herein we report the first examples of an (arene)Ru(II)/TsDPENbased Noyori-lkariya precatalyst anchored to silica through the coordinated $\eta^{6}$-arene and their application to the asymmetric transfer hydrogenation of ketones. The conversions and ee's obtained with these catalysts either rivalled or outperformed those obtained with their homogeneous counterparts as well as systems immobilized on either silica, a polymer or PEG through one of the nitrogen atoms of the TsDPEN.

\section{Results and Discussion}

Synthesis of Silica-Supported (Arene)Ru(II) Dimers (6 and 7), the Corresponding Precatalysts (8 and 9) and Molecular Precatalyst (10).

The key to immobilizing the (arene) $\mathrm{Ru}(\mathrm{II})$ fragment via the arene ligand is straightforward access to an appropriately substituted 1,4-cyclohexadiene which can be further modified to introduce a silanizable triethoxysilyl group after coordination to ruthenium (Scheme 1). This was achieved via the cobalt catalyzed cycloaddition between 2,3-dimethyl-1,3-butadiene 1 and 3-but-1ynol 2 to afford the 1,4-cyclohexadiene 3 as a clear spectroscopically pure oil after purification by distillation (Scheme 1). ${ }^{[24]}$ The corresponding (arene)ruthenium(II) dimer 4 was prepared by reaction of 3 with ruthenium trichloride in 2 methoxyethanol and isolated as a pale orange solid in near quantitative yield by precipitation with diethyl ether. As each ruthenium fragment has a stereogenic plane, $\mathbf{4}$ could exist as a mixture of rac and meso diastereoisomers. Interestingly though, the ${ }^{1} \mathrm{H}$ NMR and ${ }^{13} \mathrm{C}\left\{{ }^{1} \mathrm{H}\right\}$ NMR spectra appear to contain only one set of resonances with no evidence for a second diastereoisomer; this may be due to either (i) formation of a single diastereoisomer, (ii) rapid interconversion of a mixture of diastereoisomers via facile dissociation of the kinetically labile chloride bridges or (iii) formation of a mixture of diastereoisomers that are indistinguishable by NMR spectroscopy. Crystallisation of $\mathbf{4}$ by slow evaporation of a concentrated ethanol solution at room temperature gave crystals suitable for a single-crystal X-ray study; a perspective view of the molecular structure is shown in Figure 1. The molecular structure shows that the crystal used to collect the data contains the $(S, R)$ anti-diastereoisomer although this does not conclusively prove that $\mathbf{4}$ exists as a single diastereoisomer in solution. The $\mathrm{Ru}-\mathrm{C}$ (arene) bond lengths fall between 2.149 (3) and 2.200(3) Å with a mean value of ca. $2.18 \AA$, which is within the range reported for related complexes such as [(p-cymene) $\left.\mathrm{RuCl}_{2}\right]_{2}$ (range: 2.13(1)-2.18(2) $\AA$; mean: ca. 2.16 $\AA),{ }^{[25]}\left[\left(\mathrm{C}_{6} \mathrm{H}_{5} \mathrm{OCH}_{2} \mathrm{CH}_{2} \mathrm{OH}\right) \mathrm{RuCl}_{2}\right]_{2}$ (range: 2.14(1)-2.21(1) $\AA$; mean: ca. $2.17 \AA$ А $\left.),{ }^{[26]}\left[1,4-\mathrm{C}_{6} \mathrm{H}_{4}\left(\mathrm{CH}_{2} \mathrm{CO}_{2} \mathrm{Et}\right)_{2}\right) \mathrm{RuCl}_{2}\right]_{2}$ (range: 2.150(5)-2.182(5) $\AA$; mean: ca. $2.17 \quad \AA)^{[27]}$ and $\left[\left(\mathrm{C}_{6} \mathrm{H}_{5} \mathrm{CH}_{2} \mathrm{CO}_{2} \mathrm{H}\right) \mathrm{RuCl}_{2}\right]_{2}$ (range: 2.15(1)-2.184(8) $\AA$; mean: ca. $2.16 \AA$ ). ${ }^{[28]}$ The Ru-Cl bond lengths of $2.4152(8) \AA$ (monodentate) and ca. $2.44 \AA$ (bridging) are also unexceptional and similar to the mean value for those observed in this series of (arene)Ru-dimers (ca. $2.40 \AA$ (monodentate) and ca. $2.45 \AA$ (bridging).

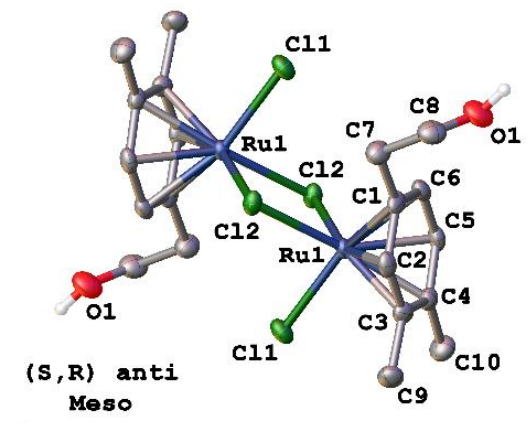

Figure 1. Crystal structure of [(2-(3,4-dimethylphenyl)ethan-1-ol) $\left.\mathrm{RuCl}_{2}\right]_{2}$ (4). Hydrogen atoms have been omitted for clarity except those of the hydroxyl groups. Ellipsoids are drawn at the $50 \%$ probability level.

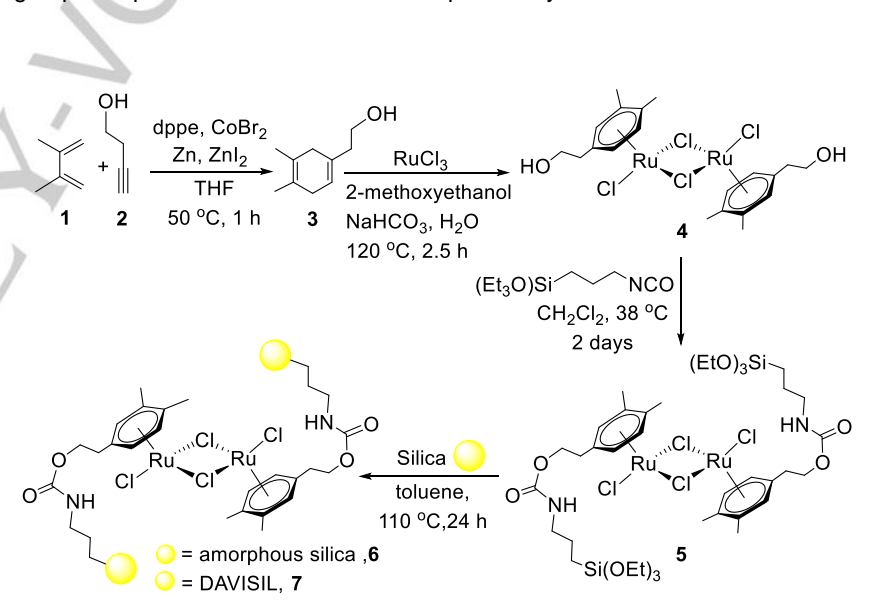

Scheme 1. Synthesis of silica-supported (arene)Ru(II) dimers 6 and 7.

The silanizable triethoxysilane-containing extension was introduced by reaction of the alcohol 4 with triethoxy(3isocyanatopropyl)silane to afford the corresponding carbamate $\mathbf{5}$ in $80 \%$ yield after washing the crude product with dry hexane to remove excess isocyanate. The identity of $\mathbf{5}$ was established by ${ }^{1} \mathrm{H}$ NMR spectroscopy, IR spectroscopy and the electrospray mass spectrum which contained an ion with an $\mathrm{m} / \mathrm{z}$ at 534.1011 corresponding to the $[\mathrm{Ru}(\text { arene }) \mathrm{Cl}]^{+}$fragment. (Arene) $\mathrm{Ru}(\mathrm{II})$ dimer $\mathbf{5}$ is a highly versatile fragment that can be immobilised on a range of silica supports and subsequently reacted with a chiral ligand to generate a library of catalysts. Amorphous silica and DAVISIL were identified as suitable supports for our preliminary immobilisation studies; this was achieved by heating $\mathbf{5}$ and the silica in a range of solvents at reflux. Reaction times were varied and the extent of silanization determined as a function of time by filtering the reaction mixture to remove the silica and analysing the remaining solution by ${ }^{1} \mathrm{H}$ NMR spectroscopy, using 4- 
bromobenzonitrile as an internal standard to quantify the amount of 5 that had not been immobilised. The most efficient silanization was achieved in toluene after $24 \mathrm{~h}$. In addition, as the $\pi$-arene ligand is known to undergo exchange at elevated temperatures, the stability of 5 in toluene was monitored at $120^{\circ} \mathrm{C}$ for $24 \mathrm{~h}$; under these conditions there was no evidence for dissociation of the arene in $\mathbf{5}$. Under these conditions, $\mathbf{5}$ was immobilized on amorphous silica and DAVISIL to afford 6 and 7, respectively, in near quantitative yields. DAVISIL was chosen as it is a high surface area amorphous silica (pore size $6 \mathrm{~nm}, 450-560 \mathrm{~m}^{2} \mathrm{~g}^{-1}$ ) and as such the active sites are expected to be exposed and accessible on the surface of the support, whereas for mesoporous materials with a hierarchical structure such as MCM41 and SBA-15 the active sites are more likely to be encapsulated in pores; moreover a wide range of pore diameters is commercially available which will ultimately enable the influence of the pore size on catalyst efficacy to be explored in a systematic manner. The amorphous silica used for comparison has a slightly smaller pore size of $4 \mathrm{~nm}$ and a correspondingly higher BET surface area of $>700 \mathrm{~m}^{2} \mathrm{~g}^{-1}$. The ruthenium loadings of 6 and 7 were determined to be 0.023 and $0.037 \mathrm{mmol} \mathrm{g}^{-1}$, respectively, by ICP-OES which corresponds to a loading of 0.23 and 0.37 wt-\%, respectively, and the solid state ${ }^{13} \mathrm{C}$ and ${ }^{29} \mathrm{Si}$ cross-polarization magic angle spinning NMR spectra confirmed that the ruthenium dimer was immobilized onto the silica walls of an inorganosilicate network (Figure 2a).

(a)

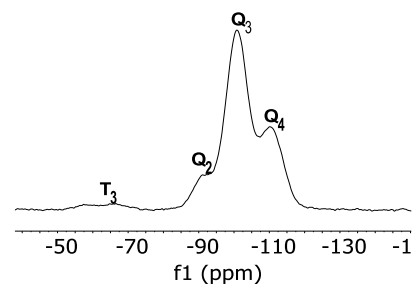

(b)

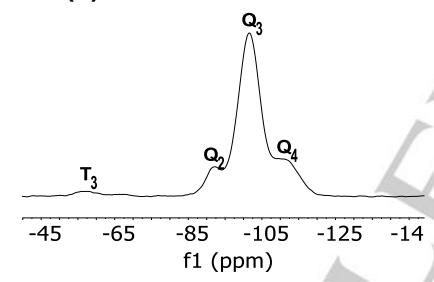

$\mathrm{NCHPh}$ carbon atoms of TsDPEN and the $\mathrm{OCH}_{2}$ of the carbamate linker and those between $\delta 120$ and 145 ppm belong to the carbon atoms of the aromatic ring of the TsDPEN and the $\eta^{6}$-arene. Moreover, the chemical shifts of the structurally relevant carbon atoms map closely to those for the homogeneous molecular benchmark 10, further confirmation for incorporation of the (arene) $\mathrm{Ru}(\mathrm{II}) / \mathrm{TsDPEN}$ precatalyst. The magic angle spinning solid state ${ }^{29} \mathrm{Si}$ spectra of 8 and $\mathbf{9}$ both contained two groups of signals typical for silica; a Q-series for inorganic silica $(\mathrm{HO})_{n} \mathrm{Si}(\mathrm{OSi})_{4-n}$ and a T-series for organic silica $\mathrm{RSi}(\mathrm{OSi})_{3}$. The $\mathrm{Q}$ series appears as a set of three poorly resolved signals at ca. $\delta$ 91, -102 and -112 ppm for $\mathrm{Q}_{2}\left((\mathrm{HO})_{2} \mathrm{Si}(\mathrm{OSi})_{2}\right), \mathrm{Q}_{3}\left((\mathrm{HO}) \mathrm{Si}(\mathrm{OSi})_{3}\right)$ and $\mathrm{Q}_{4}\left(\mathrm{Si}(\mathrm{OSi})_{4}\right)$, respectively, and is markedly more intense than the major $T_{3}$ species which is a broad ill-defined peak at $\delta-66$ ppm (Figure 2b); the disparate intensities of these resonances confirms that these catalysts are comprised mainly of inorganic silicate together with a minor amount of organic silicate resulting from immobilization of the silylated (arene) Ru(II)/TsDPEN on the walls of the silicate network. The X-ray photoelectron spectra of 8 and 9 each contained a doublet with binding energies of 462.28 $\mathrm{eV}\left(\mathrm{Ru} 3 \mathrm{p}_{1 / 2}\right)$ and $484.58 \mathrm{eV}\left(\mathrm{Ru} 3 \mathrm{p}_{3 / 2}\right)$, and $463.78 \mathrm{eV}\left(\mathrm{Ru} 3 \mathrm{p}_{1 / 2}\right)$ and $486.68 \mathrm{eV}\left(\mathrm{Ru} 3 \mathrm{p}_{3 / 2}\right)$, respectively; these values are consistent with a $\mathrm{Ru}(\mathrm{II})$ species immobilized on the surface of silica.

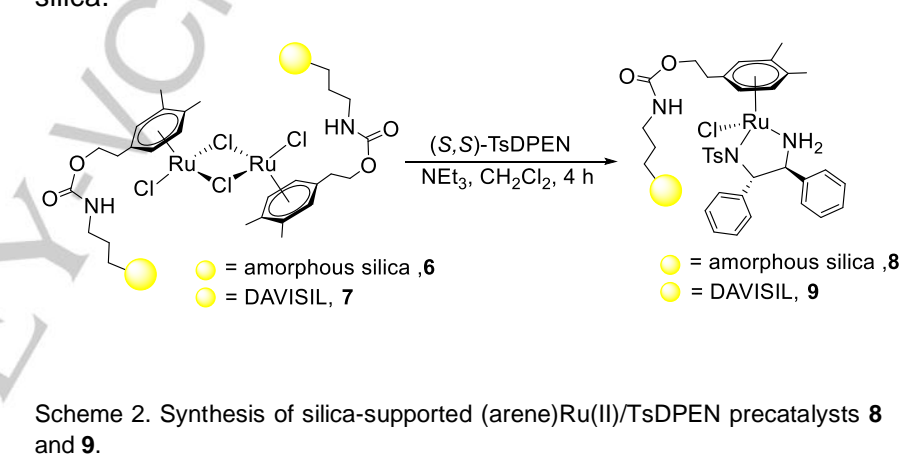

Scheme 2. Synthesis of silica-supported (arene)Ru(II)/TsDPEN precatalysts 8 and 9 .

While it is conventional to undertake comparative catalyst testing against $[(p$-cymene $) \operatorname{Ru}\{(1 S, 2 S)-T s D P E N)\} \mathrm{Cl}]$ as a soluble monomeric homogeneous pe-catalyst we chose to use [(2-(3,4dimethylphenyl)ethan-1-ol)Ru\{(1S,2S)-TsDPEN\}(CI)] (10) as it more closely represents a molecular analogue of $\mathbf{8}$ and $\mathbf{9}$ and, as such, should provide a more realistic assessment of the influence on catalyst performance of attachment to the support. Precatalyst 10 was prepared by stirring a dichloromethane solution of 4 , $(1 S, 2 S)$-TsDPEN and triethylamine for $1 \mathrm{~h}$ at RT. Although the NMR spectra, the electrospray mass spectrum and analytical data were all consistent with the formulation of $\mathbf{1 0}$, its identity was conclusively established by a single-crystal X-ray study; a perspective view of the molecular structure is shown in Figure 3. The molecular structure shows that the crystal used to collect the data contains a single diastereoisomer which is consistent with the NMR spectroscopic data as there is no evidence for the presence of multiple species in either the ${ }^{1} \mathrm{H}$ or ${ }^{13} \mathrm{C}\left\{{ }^{1} \mathrm{H}\right\}$ NMR spectra; however, this is not conclusive as resonances may be coincident or other diastereoisomers may be present but only as a minor component. Figure 3 shows that the ruthenium atom adopts a piano stool pseudo-octahedral geometry with the $\eta^{6}$ arene, chloride and the $(1 S, 2 S)$-DPEN completing the coordination sphere. The Ru-C(arene) bond lengths fall in the range 2.162(5)-2.217(5) $\AA$ which is consistent with those reported 
for related complexes such as $[(p$-cymene $) \operatorname{Ru}\{(1 S, 2 S)$ TsDPEN\}(Cl)] (range: 2.141(7)-2.239(8) $\AA$; mean: ca. $2.19 \AA$ A), ${ }^{[29]}$ $\left[\left\{1,4-\mathrm{C}_{6} \mathrm{H}_{4}(\mathrm{Me})\left(\mathrm{C}_{4} \mathrm{H}_{8} \mathrm{OH}\right)\right\} \mathrm{Ru}\{(1 \mathrm{~S}, 2 \mathrm{~S})-\mathrm{TsDPEN}(\mathrm{Cl})]\right.$ (range: 2.166(3)-2.236(3) $\AA$; mean: ca. $2.20 \AA \AA$ ), ${ }^{[30]}$ and $\left[\left\{\mathrm{C}_{6} \mathrm{H}_{5}\left(\mathrm{OCH}_{2} \mathrm{CH}_{2} \mathrm{OH}\right)\right\} \mathrm{Ru}\{(1 \mathrm{~S}, 2 \mathrm{~S})-\mathrm{TsDPEN}\}(\mathrm{Cl})\right]$ (range: 2.18(2)2.23(2) $\AA$; mean: ca. $2.2 \AA$ ). ${ }^{[31]}$ The $\mathrm{Ru}-\mathrm{N}(1)$ and $\mathrm{Ru}-\mathrm{N}(2)$ bond lengths of 2.104(5) $\AA$ and 2.162(4) $\AA$, respectively, are also unexceptional and similar to those in this representative selection of precatalysts.

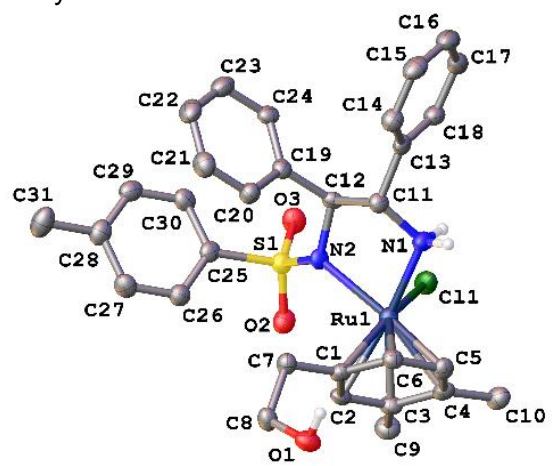

Figure 3. Crystal structure of [(2-(3,4-dimethylphenyl)ethan-1-ol)Ru\{(1S,2S)TsDPEN\}(Cl)] (10). Hydrogen atoms have been omitted for clarity with the exception of those bound to heteroatoms. Ellipsoids are drawn at the $50 \%$ probability level.

\section{Asymmetric Transfer Hydrogenation of Ketones}

Preliminary catalyst screening and optimization focused on acetophenone as the substrate of choice as this is often employed as the benchmark for evaluating new catalysts; optical purity and yields were determined by GC analysis and full details are listed in Table 1. Reactions were initially conducted using catalyst generated in situ by reaction of either 6 or $\mathbf{7}$ with a slight excess of $(S, S)$-TsDPEN and triethylamine in dichloromethane for $1 \mathrm{~h}$ at $55{ }^{\circ} \mathrm{C}$, prior to addition of the reducing agent and substrate; comparative testing was also undertaken with pre-prepared catalysts 8 and $\mathbf{9}$. Table 1 shows that catalysts generated from either $\mathbf{6}$ or $\mathbf{7}$ and $(S, S)$-TsDPEN gave TOFs and ee's that either matched or outperformed those obtained with their soluble molecular counterpart 10 , after $1.5 \mathrm{~h}$ at $55^{\circ} \mathrm{C}$ using formic acidtriethylamine azeotrope as the hydrogen donor (Table 1, entries 1-2 and 5). Moreover, the ee's and yields obtained with both silicasupported systems match those reported for catalyst generated from $[(p$-cymene) Ru $\{(S, S)$-TsDPEN $\}(\mathrm{Cl})]$ and triethylamine at a reaction temperature of $60{ }^{\circ} \mathrm{C},{ }^{[2 b]}$ and either compete with or outperform existing silica-supported (arene)Ru/TsDPEN-based catalysts immobilized through the nitrogen atom of the TsDPEN ligand, including magnetically retrievable mesoporous silica microcapsules ${ }^{[6,6 h]}$ and (arene)Ru/TsDPEN confined in amphiphilic-modified nanocages of SBA-16, ${ }^{[32 a, b]}$ or supported on silica gel, mesoporous MCM-41, SBA- $15,{ }^{[6 e, 6 \mathrm{~d}, 6 \mathrm{f}, 6 \mathrm{6g}]}$ or siliceous mesocellular foam (SMF). ${ }^{[6,6 i]}$ Reassuringly, the ee's and TOF's obtained with preformed catalysts 8 and $\mathbf{9}$ also match those obtained with catalyst generated in situ which suggests that in situ formation of the catalyst under these conditions is efficient and essentially quantitative (Table 1 , entries 3 and 4). The slightly higher yield obtained with $\mathbf{9}$ compared to $\mathbf{8}$ is most likely due to the increased efficiency in ruthenium loading, however, at this early stage, speculation as to the origin of minor differences in activity between catalyst supported on amorphous silica and Davisil is not warranted. However, DAVISIL-supported 9 was identified as the system of choice to undertake further studies and substrate screening (vide infra) as the more tightly controlled chemical and structural properties of DAVISIL silicas will enable a systematic investigation of the influence of the support on catalyst efficacy to be conducted. A survey of catalysts generated in situ by addition of various chiral diamines and amino alcohols including $(S, S)$-TsDPEN, $(R, R)$-Ph-pyBOX, (1R,2S)-1-amino-2indanol and $(S, S)$-TsCYDN revealed $(S, S)$-TsDPEN generated the most efficient catalyst. Following this, precatalyst $\mathbf{9}$ was used to further explore the influence of varying reaction conditions and reagents on catalyst performance including solvent, temperature, time, catalyst loading and hydrogen donor. Variation of the hydrogen donor revealed that formic acid-triethylamine azeotrope gave the best combination of TOF and ee whereas $\mathrm{NaBH}_{4}$ and $\mathrm{Me}_{2} \mathrm{NHBH}_{3}$ both gave near quantitative yields but very poor ee's and formate salts gave negligibly low conversions. As expected, lowering the reaction temperature resulted in a reduction in activity such that a conversion of $46 \%$ was reached at $50{ }^{\circ} \mathrm{C}$ with a slight improvement in the ee to $98 \%$; the conversion could be improved by extending the reaction time with no loss in ee. Lowering the reaction temperature further to $45^{\circ} \mathrm{C}$ resulted in a marked reduction in conversion to $18 \%$ after $1.5 \mathrm{~h}$ which increased to $81 \%$ after $5 \mathrm{~h}$, in both cases with an ee of $98 \%$. Finally, at $25{ }^{\circ} \mathrm{C}$ a reaction time of $24 \mathrm{~h}$ was required to reach $50 \%$ conversion with an ee of $98 \%$; although more sluggish than reactions conducted at higher temperatures, the enantioselectivity and TOF were comparable to those obtained by Noyori using $0.5 \mathrm{~mol}-\%$ [ $\left(\eta^{6}\right.$-mesitylene $\left.) \mathrm{Ru}\{(S, S)-T s D P E N)(\mathrm{Cl})\right]$ as precatalyst. ${ }^{[2 \mathrm{~b}]} \mathrm{A}$ reduction in the catalyst loading to $0.17 \mathrm{~mol}-\%$ resulted in a slightly lower conversion of $77 \%$ with an enantioselectivity of $97 \%$ while a further reduction in the loading to $0.085 \mathrm{~mol}-\%$ gave a much lower conversion of $26 \%$ but with an enantioselectivity of $99 \%$. As there have been several reports of efficient ATH of ketones and imines in water using catalysts generated from silica-supported TsDPEN ${ }^{[6 c, 6 d, 6 h, 32 a, b]}$ a series of reactions were conducted in water, ethanol and methanol; however, in each case conversions were either low or negligible and, as such, all further reactions were performed in neat $\mathrm{HCOOH}-\mathrm{NEt}_{3}$ azeotrope. A study of the conversion and ee as a function of time using $0.17 \mathrm{~mol}-\% 9$ in neat $\mathrm{HCOOH} / \mathrm{NEt}_{3}$ azeotrope at $50{ }^{\circ} \mathrm{C}$ revealed that complete conversion was achieved after $2 \mathrm{~h}$, which corresponds to an initial TOF of $1085 \mathrm{~h}^{-}$ 1 (Figure 4, conversion - and ee $\mathbf{\Delta}$ ). For comparison, the corresponding conversion-time profile using $0.17 \mathrm{~mol}-\% \mathbf{1 0}$ gave a markedly lower initial TOF of $260 \mathrm{~h}^{-1}$ (Figure 4, conversion $\bullet$ and ee $\diamond$.

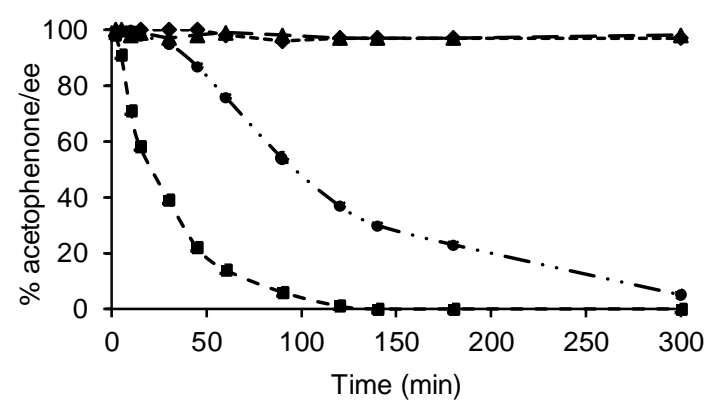

Figure 4. Reaction profile as a function of time for the asymmetric transfer hydrogenation of acetophenone in neat $\mathrm{HCOOH} / \mathrm{NEt}_{3}$ azeotrope using (a) 0.17 mol-\% 9 (\%conversion and \%ee $\Delta$ ) and (b) 0.17 mol-\% 10 (\% conversion • and \% ee $\bullet$ ). 
Table 1. Asymmetric transfer hydrogenation of acetophenone using precatalysts generated from silica-supported ruthenium dimers $\mathbf{6}$ and $\mathbf{7}$ their precatalysts $\mathbf{8}$ and 9 or molecular precatalyst 10. ${ }^{\text {[a] }}$

\begin{tabular}{|c|c|c|c|c|c|c|c|}
\hline Entry & Catalyst system & H-donor & Mol-\% cat & $\operatorname{Temp}\left({ }^{\circ} \mathrm{C}\right)$ & Solvent & $\begin{array}{l}\text { Conv. } \% \\
\left(\operatorname{TOF}\left(\mathrm{h}^{-1}\right)\right)^{b}\end{array}$ & ee $(\%)^{b, c}$ \\
\hline 1 & $(S, S)-T s D P E N / 6$ & $\mathrm{HCO}_{2} \mathrm{H} / \mathrm{NEt}_{3}$ & 0.22 & 55 & - & $90(272)$ & 96 \\
\hline 2 & $(S, S)-T s D P E N / 7$ & $\mathrm{HCO}_{2} \mathrm{H} / \mathrm{NEt}_{3}$ & 0.34 & 55 & - & 99 (194) & 97 \\
\hline 3 & 8 & $\mathrm{HCO}_{2} \mathrm{H} / \mathrm{NEt}_{3}$ & 0.22 & 55 & - & $88(266)$ & 97 \\
\hline 4 & 9 & $\mathrm{HCO}_{2} \mathrm{H} / \mathrm{NEt}_{3}$ & 0.34 & 55 & - & 98 (192) & 97 \\
\hline 5 & 10 & $\mathrm{HCO}_{2} \mathrm{H} / \mathrm{NEt}_{3}$ & 1.0 & 55 & - & $99(66)$ & 96 \\
\hline 6 & $(R, R)-\mathrm{Ph}-\mathrm{pyBOX} / 7$ & $\mathrm{HCO}_{2} \mathrm{H} / \mathrm{NEt}_{3}$ & 0.34 & 55 & - & $2(3)$ & nd \\
\hline 7 & $\begin{array}{l}(1 R, 2 S)-1 \text {-amino-2- } \\
\text { indanol/ } 7\end{array}$ & $\mathrm{HCO}_{2} \mathrm{H} / \mathrm{NEt}_{3}$ & 0.34 & 55 & - & $3(6)$ & nd \\
\hline 8 & $(S, S)-T s C Y D N / 7$ & $\mathrm{HCO}_{2} \mathrm{H} / \mathrm{NEt}_{3}$ & 0.34 & 55 & - & $49(96)$ & 90 \\
\hline 9 & 9 & $\mathrm{HCO}_{2} \mathrm{H} / \mathrm{NE}_{3}$ & 0.17 & 55 & - & 77 (392) & 97 \\
\hline 10 & 9 & $\mathrm{Me}_{2} \mathrm{NHBH}_{3}$ & 0.17 & 55 & - & $99(388)$ & 7 \\
\hline 11 & 9 & $\mathrm{NaBH}_{4}$ & 0.17 & 55 & water & $98(384)$ & 3 \\
\hline 12 & 9 & $\mathrm{KO}_{2} \mathrm{CH}$ & 0.17 & 55 & water & $5(20)$ & 91 \\
\hline 13 & 9 & $\mathrm{NH}_{4} \mathrm{O}_{2} \mathrm{CH}$ & 0.17 & 55 & water & $0(0)$ & nd \\
\hline 14 & 9 & $\mathrm{HCO}_{2} \mathrm{H}$ & 0.17 & 55 & - & $0(0)$ & nd \\
\hline 15 & 9 & $\mathrm{HCO}_{2} \mathrm{H} / \mathrm{NEt}_{3}$ & 0.085 & 55 & - & $26(203)$ & 99 \\
\hline 16 & 9 & $\mathrm{HCO}_{2} \mathrm{H} / \mathrm{NEt}_{3}$ & 0.17 & 50 & - & $46(180)$ & 98 \\
\hline 17 & 9 & $\mathrm{HCO}_{2} \mathrm{H} / \mathrm{NEt} 3$ & 0.17 & 45 & - & $18(71)$ & 98 \\
\hline $18^{[d]}$ & 9 & $\mathrm{HCO}_{2} \mathrm{H} / \mathrm{NEt}_{3}$ & 0.17 & 25 & - & $50(12)$ & 98 \\
\hline 19 & 9 & $\mathrm{HCO}_{2} \mathrm{H} / \mathrm{NEt}_{3}$ & 0.17 & 55 & water & $0(0)$ & nd \\
\hline 20 & 9 & $\mathrm{HCO}_{2} \mathrm{H} / \mathrm{NEt}_{3}$ & 0.17 & 55 & $\mathrm{EtOH}$ & $14(55)$ & 49 \\
\hline 21 & 9 & $\mathrm{HCO}_{2} \mathrm{H} / \mathrm{NEt}_{3}$ & 0.17 & 55 & $\mathrm{MeOH}$ & $12(47)$ & 54 \\
\hline
\end{tabular}

[a] Reactions were carried out with $0.5 \mathrm{mmol}$ of acetophenone using precatalyst generated from silica-supported ruthenium dimers 6 and 7 or pre-prepared silicasupported (arene)Ru/TsDPEN precatalysts $\mathbf{8}, \mathbf{9}$ or $\mathbf{1 0}$ in neat $\mathrm{HCOOH}-\mathrm{NEt}$ 3 azeotrope for 90 min (unless otherwise stated) under the specified conditions of temperature, S/C ratio, hydrogen donor and solvent. [b] Determined by gas chromatography equipped with a CP-Chirasil-DEX CB column using decane as internal standard. [c] Configuration was determined to be $S$ from the sign of the optical rotation. [d] Reaction time of $24 \mathrm{~h}$.

The improved performance of $\mathbf{9}$ compared with $\mathbf{1 0}$ could be due to either 'confinement', ${ }^{[3]}$ site isolation ${ }^{[34]}$ or preorganization of the $\mathrm{C}-\mathrm{H} / \pi$ interaction arising from attachment of the $\eta^{6}$-arene ring to the silica $^{[4 m, 35]}$ and further catalyst modifications are currently underway to explore the origin of this enhancement. Gratifyingly, the TOF obtained with $\mathbf{9}$ also appears to be significantly higher than Noyori-lkariya catalysts immobilized on mesoporous silica, ${ }^{[6 f, 6 h-i, 7 g, 9 a, 32 b]}$ polystyrene, ${ }^{[7 b, 7 d, 7 f]}$ or polyethylene glycol. ${ }^{[8 a-c, 9 b]}$ Based on the above screening study, a temperature of $50^{\circ} \mathrm{C}$ and reaction time of $5 \mathrm{~h}$ was considered to be the best compromise to explore the substrate scope and efficacy of DAVISIL silicasupported 9.

Having identified optimum conditions and obtained encouraging conversions and ee's for the benchmark transfer hydrogenation of acetophenone, catalyst testing was extended to a range of aryl and heteroaryl ketones to explore and assess the scope and limitations of DAVISIL-supported precatalyst $\mathbf{9}$ and its molecular counterpart 10 (Table 2). Good to excellent conversions and high ee's to the corresponding secondary alcohol were obtained across a range of electron deficient 2-, 3and 4-substituted ketones (Table 2, entries 1-10) and in most cases, silica-supported 9 either rivalled or outperformed its 
molecular counterpart 10. Moreover, the TOFs and ee obtained with $\mathbf{9}$ are comparable to or better than those previously reported for (arene)Ru/TsDPEN precatalysts supported on mesoporous silica $^{[6 \mathrm{cc}, 6 \mathrm{~d}, 6 \mathrm{ee}, 6 \mathrm{~g}]}$ and siliceous mesocellular foam ${ }^{[6,6 \mathrm{i}]}$ and encapsulated within nanocages of amphiphilic SBA-16 ${ }^{[32]}$ as well as PEG-based polymers ${ }^{[8 a, 8 b, 8 c, 9 b]}$ and styrene-based systems such as a poly(styrene-1-phosphonate styrene) inorganic zirconium phosphate-phosphonate hybrid, ${ }^{[7 a]}$ phosphonatecontaining polystyrene copolymer, ${ }^{[7 \mathrm{~b}]}$ cross-linked polystyrene, ${ }^{[7 \mathrm{~d}]}$ and amphiphilic polystyrene. ${ }^{[7]}$ While high ee's were obtained with each of the 4-substituted acetophenones examined, the ee's obtained with their 2-substituted counterparts were more disparate and varied between $87-98 \%$. For example, reduction of 2-bromoacetophenone gave 1-(2-bromophenyl)ethan-1-ol with an ee of $98 \%$ whereas its 2-chloro-substituted counterpart gave the corresponding secondary alcohol in $87 \%$ ee. High conversions and excellent ee's were also obtained for arylketones substituted with electron donating groups at the 2-, 3- and 4positions (Table 2, entries 11-13) as well as 2-acetonaphthone (Table 2, entry 14) all of which gave the corresponding alcohol in $99-100 \%$ ee. Even though the p-methoxyacetophenone only reached $60 \%$ conversion after $5 \mathrm{~h}$ under these conditions (Table 2 , entry 11$)$, the ee of $99 \%$ is an improvement on that reported for $\left[\left(\eta^{6} \text {-mesitylene }\right) \operatorname{Ru}\{(S, S) \text {-TsDPEN }\} C l\right]^{[2 b]}$ as well as the majority of silica, ${ }^{[6]}$ polymer ${ }^{[7,14]}$ and PEG-supported ${ }^{[8]}$ catalysts; moreover, complete conversion was obtained by extending the reaction time to $12 \mathrm{~h}$ with no loss in ee. The same protocol was extended to the asymmetric transfer hydrogenation of 2acetylfuran and 2-acetylthiophene which gave $91 \%$ and $78 \%$ conversion to (S)-1-(2-furyl)ethanol and (S)-1-(2-thienyl)ethanol, respectively, both with $100 \%$ ee (Table 2, entries, 15 and 16). While 9 tolerated the steric hindrance of a variety of orthosubstituted acetophenones, negligible conversions were obtained with 2,2-dimethyl-1-phenylpropan-1-one, 1-tetralone, 1acetonaphthone, and cyclopropyl(phenyl)methanone, which are sterically much more demanding substrates. Unfortunately, $\mathbf{9}$ was also unable to reduce 3- and 4-acetylpyridine as quantitative amounts of starting material were consistently recovered even after an extended reaction time of $10 \mathrm{~h}$. Reasoning that the presence of a large excess of nitrogen donor could result in ligand substitution of either the TSDPEN or chloride and afford a less active or inactive pyridine-saturated species, pre-treatment of a mixture of $0.17 \mathrm{~mol}-\% 9$ and $\mathrm{HCO}_{2} \mathrm{H} / \mathrm{NEt}_{3}$ azeotrope with 0.5 mmol of 3 -acetylpyridine at $50{ }^{\circ} \mathrm{C}$ for $15 \mathrm{~min}$ resulted in a significant reduction in activity as a conversion of only $14 \%$ with an ee of $98 \%$ was obtained for the reduction of acetophenone, compared with complete conversion and an ee of $98 \%$ under the same conditions but in the absence of 3 -acetylpyridine. In a modification of this investigation, the conversion of acetophenone as a function of 3-acetylpyridine addition time was investigated by running a series of hydrogenations in parallel and adding 3acetylpyridine after $0.5 \mathrm{~h}, 1 \mathrm{~h}$ and $2 \mathrm{~h}$ and working each reaction up after $5 \mathrm{~h}$; the conversion profile of $54 \%(0.5 \mathrm{~h}), 81 \%(1 \mathrm{~h})$ and $98 \%(2 \mathrm{~h})$ shows that addition of 3-acetylpyridine results in near instantaneous deactivation of the catalyst as the conversions obtained at each time interval are similar to those obtained for the same reaction in the absence of 3-acetylpyridine. In a scale-up experiment, the asymmetric transfer hydrogenation of 2bromoacetophenone on a $10 \mathrm{mmol}$ scale in $5.0 \mathrm{~mL}$ of the $\mathrm{HCO}_{2} \mathrm{H} / \mathrm{NEt}_{3}$ azeotrope gave complete conversion to 1-(2bromophenyl)ethan-1-ol with an ee of $98 \%$ after $9 \mathrm{~h}$ at $50{ }^{\circ} \mathrm{C}$.
The reusability of $\mathbf{9}$ was investigated for the benchmark transfer hydrogenation of acetophenone under the conditions described above to assess the robustness and longevity of the catalyst and the potential for integration into a continuous flow reactor set-up. Recycle experiments were conducted on a larger scale to try and overcome the practical problems associated with recovering the catalyst from a small-scale reaction. Reactions were run for $4 \mathrm{~h}$ to avoid complete conversion which would enable any change in activity to be observed. The catalyst was recycled by quenching the reaction with a large excess of ethyl acetate, recovering the catalyst by centrifugation, and removing the organic phase with a syringe, then recharging the flask with additional portions of $\mathrm{HCO}_{2} \mathrm{H}_{/} \mathrm{NEt}_{3}$ azeotrope and acetophenone. ${ }^{[7 \mathrm{~d}]}$ Following this protocol, 9 gave consistently high ee's (>99 \%) across five cycles although conversions dropped gradually from $99 \%$ in the first run to $77 \%$ and $63 \%$ in the second and third runs, respectively, after which they remained constant (Figure 5). ICP analysis of the organic phase collected during the first three runs revealed leaching of the ruthenium to be the primary reason for the decrease in conversion as the ruthenium content dropped by $18 \%$ in run 1 and $8 \%$ and $5 \%$ in runs 2 and 3 , respectively; which closely correlates with the reduction in conversion. To this end, Hintermair has recently provided convincing evidence for two deactivation/inhibition pathways for (arene)(TsDPEN)Ru-H, one of which involves gradual dissociation of the arene ligand while the other involves competitive inhibition of the unsaturated intermediate by excess base. ${ }^{[36]}$ Even though the activity dropped during the first two runs, the stable activity profile during successive runs suggests that the remaining supported ruthenium sites are robust with respect to leaching and/or deactivation and inhibition. Future studies will aim to establish why the remaining active sites are more robust after initial leaching and further improve the stability profile to integrate the system into a continuous flow process.

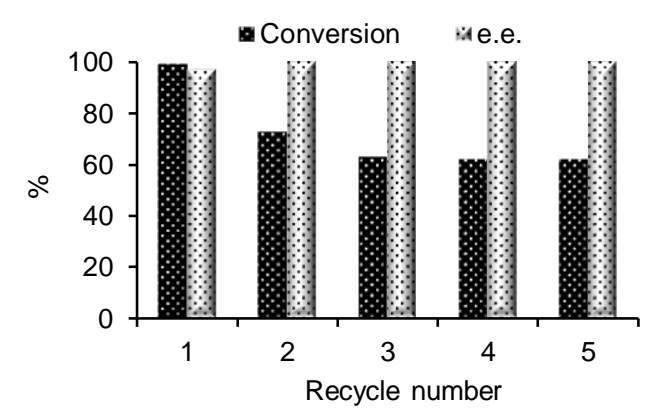

Figure 5. Recycle study for the transfer hydrogenation of acetophenone using precatalyst 9 and a reaction time of $4 \mathrm{~h}$. 
Table 2. Asymmetric Transfer Hydrogenation of Ketones in Formic Acid-Triethylamine Azeotrope using Silica-Supported Precatalyst 9 and Molecular Precatalyst 10. [a]

\begin{tabular}{|c|c|c|c|c|c|}
\hline \multirow[b]{2}{*}{ Entry } & \multirow[b]{2}{*}{ Substrate } & \multicolumn{2}{|c|}{ Precatalyst 9} & \multicolumn{2}{|c|}{ Precatalyst 10} \\
\hline & & Conv $(\%) /\left(\operatorname{TOF}\left(\mathrm{h}^{-1}\right)\right)^{b}$ & ee $(\%)^{b, c}$ & Conv $(\%) /\left(\operatorname{TOF}\left(\mathrm{h}^{-1}\right)\right)^{b}$ & ee $(\%)^{b, c}$ \\
\hline 1 & 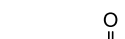 & $100(118)$ & 93 & 95 (112) & 92 \\
\hline 2 & & $99(116)$ & 98 & $100(118)$ & 75 \\
\hline 3 & & $91(107)$ & 94 & $100(118)$ & 94 \\
\hline 4 & & $100(118)$ & 94 & $100(118)$ & 95 \\
\hline 5 & & $100(118)$ & 92 & $100(118)$ & 90 \\
\hline 6 & & $80(92)$ & 87 & (112) & 83 \\
\hline 7 & & $100(118)$ & 96 & $100(118)$ & 93 \\
\hline 8 & & $100(118)$ & 00 & $98(115)$ & 79 \\
\hline 9 & & $99(116)$ & 97 & $96(113)$ & 97 \\
\hline 10 & & $99(116)$ & 93 & $100(118)$ & 93 \\
\hline 11 & & $60(71)$ & $>99$ & $90(106)$ & $>99$ \\
\hline 12 & & $100(118)$ & $>99$ & $100(118)$ & $>99$ \\
\hline 13 & & $98(115)$ & 99 & $99(116)$ & 99 \\
\hline 14 & & $100(118)$ & 97 & $100(118)$ & 98 \\
\hline 15 & & $91(107)$ & 100 & 95 (112) & 99 \\
\hline 16 & & $78(92)$ & 100 & $88(103)$ & 97 \\
\hline
\end{tabular}

[a] Reactions conditions: $0.5 \mathrm{mmol}$ of acetophenone, $0.17 \mathrm{~mol}$-\% silica supported (arene)Ru/Ts-DPEN precatalyst 9 , in neat $5: 2$ formic acid:triethylamine ( $0.25 \mathrm{~mL}$, $3.0 \mathrm{mmol}$ of $\mathrm{HCO}_{2} \mathrm{H}$ ), $50{ }^{\circ} \mathrm{C}, 5 \mathrm{~h}$. [b] Determined by gas chromatography equipped with a CP-Chirasil-DEX CB column using decane as internal standard. [c] Configuration determined to be $S$ from the sign of the optical rotation. 


\section{Conclusion}

In conclusion, this paper describes the first example of a NoyoriIkariya precatalyst anchored to amorphous silica and DAVISIL by immobilization through the $\eta^{6}$-coordinated arene ligand, which was prepared via a straightforward and versatile cobalt-catalyzed [4+2] cycloaddition between a homopropargylic alcohol and a diene. The derived catalysts (arene)Ru(II)/TsDPEN@silica and (arene)Ru(II)/TsDPEN@DAVISIL exhibit excellent activity for the asymmetric transfer hydrogenation of a range of electron-rich and electron-poor aromatic ketones, giving good conversions and high ee's under mild reaction conditions. Catalyst generated in situ, by reaction of the corresponding silica-supported (arene)Ru(II) dimer with (S,S)-TsDPEN immediately prior to addition of substate and hydrogen donor, either competed with or outperformed its preformed counterpart $[($ arene $) \operatorname{Ru}\{(S, S)$ TsDPEN)Cl]@silica, which presents numerous practical advantages for catalyst optimization, substrate screening and reaction diversification. Gratifyingly, the TOFs and ee's obtained with these catalysts rivalled those previously reported for catalysts immobilized on either silica or polymer through a nitrogen atom of the Ts-DPEN ligand. High ee's were maintained during recycle studies, however, the conversion dropped steadily over the first three runs due to gradual leaching of the ruthenium. These are encouraging results and provide a platform for further studies that will apply this immobilization strategy to prepare (arene) $\mathrm{Ru}(\mathrm{II}) /(\mathrm{Ts}$-DPEN) precatalysts supported on a range of DAVISIL silicas as well as functionalized ordered mesoporous silicas that can be integrated into a continuous flow process for scale-up or that can be used to develop multifunctional catalysts for cascade reaction sequences and the conversion of biomass derived substrates into value-added products.

\section{Experimental Section}

Synthesis of 2-(4,5-Dimethylcyclohexa-1,4-dien-1-yl)ethan-1-ol (3). According to the literature method, ${ }^{[24 b]} \mathrm{Zn}$ powder $(0.28 \mathrm{~g}, 4.22 \mathrm{mmol}), \mathrm{Znl}_{2}$ $(1.40 \mathrm{~g}, 4.38 \mathrm{mmol}), \mathrm{CoBr}_{2}(0.48 \mathrm{~g}, 2.19 \mathrm{mmol})$, and DPPE (0.86 g, 2.15 $\mathrm{mmol})$ were added to a three-neck flask $(250 \mathrm{~mL})$ and stirred in dry THF $(30 \mathrm{~mL})$ at room temperature. 1,3-Dimethyl-butadiene $(13.5 \mathrm{~mL}, 118$ $\mathrm{mmol}$ ) was added to the reaction mixture after 5 minutes, followed by but3-yn-1-ol $(7.9 \mathrm{~mL}, 105 \mathrm{mmol})$. The resulting mixture was stirred for 5 mins and then heated to $50^{\circ} \mathrm{C}$ for one hour, after which the solvent was removed under reduced pressure. The crude mixture was purified by vacuum distillation $\left(1 \mathrm{mmHg}, 115-121^{\circ} \mathrm{C}\right)$ to afford diene 3 in $63 \%$ yield $(10.1 \mathrm{~g}) .{ }^{1} \mathrm{H} \mathrm{NMR}\left(300 \mathrm{MHz}, \mathrm{CDCl}_{3}, \delta\right): 5.49-5.41(\mathrm{~m}, 1 \mathrm{H},=\mathrm{CH}), 3.70-3.53$ (m, 2H. $\mathrm{CH}_{2} \mathrm{OH}$ ), 2.63-2.39 (m, 4H, $\mathrm{CH}_{2}$ ), 2.21-2.14 (m, 2H, $\left.\mathrm{C}_{2} \mathrm{CH}_{2} \mathrm{OH}\right)$, $1.60\left(\mathrm{~s}, 6 \mathrm{H}, \mathrm{CH}_{3}\right) .{ }^{13} \mathrm{C}\left\{{ }^{1} \mathrm{H}\right\} \mathrm{NMR}(75 \mathrm{MHz}$, DMSO, $\delta): 104.1,102.6,95.8$, $87.5,87.2,83.4,60.4,36.2,16.9,16.3$.

Synthesis of $\left[\operatorname{RuCl}_{2}\{2 \text {-(3,4-dimethylphenyl)ethan-1-ol }\}\right]_{2}$ (4). According to the literature, ${ }^{[37]}$ a suspension of $\mathrm{RuCl}_{3} . \mathrm{H}_{2} \mathrm{O}(1.1 \mathrm{~g}, 5.3 \mathrm{mmol})$ and $\mathrm{NaHCO}_{3}(0.45 \mathrm{~g}, 5.3 \mathrm{mmol})$ in a mixture of 2-methoxyethanol: $\mathrm{H}_{2} \mathrm{O}(11 \mathrm{~mL}$, 10:1) was added 2-(4,5-dimethylcyclohexa-1,4-dien-1-yl)ethan-1-ol 3 (3.2 $\mathrm{g}, 21.2 \mathrm{mmol}$ ). The resulting mixture was heated at $120^{\circ} \mathrm{C}$ for $2.5 \mathrm{~h}$ after which time half of the solvent was removed under reduced pressure and diethyl ether added $(10 \mathrm{~mL})$ to precipitate an orange solid. The solid was filtered, washed with $\mathrm{Et}_{2} \mathrm{O}$ and dried to obtain the dimer $\mathbf{4}$ as an orange powder in $49 \%$ yield $(0.9 \mathrm{~g}) .{ }^{1} \mathrm{H} \mathrm{NMR}(300 \mathrm{MHz}$, DMSO, $\delta): 5.81$ (d, $J=$ $5.6 \mathrm{~Hz}, 1 \mathrm{H}, \operatorname{Ar} \underline{\mathrm{H}}), 5.70(\mathrm{~s}, 1 \mathrm{H}, \mathrm{Ar} \underline{\mathrm{H}}), 5.58(\mathrm{~d}, J=5.6 \mathrm{~Hz}, 1 \mathrm{H}, \mathrm{Ar} \underline{\mathrm{H}}), 4.76(\mathrm{t}$, $J=5.1 \mathrm{~Hz}, 1 \mathrm{H}, \mathrm{OH}$ ), $3.68\left(\mathrm{qd}, J=6.5,3.3 \mathrm{~Hz}, 2 \mathrm{H}, \mathrm{CH}_{2} \mathrm{OH}\right) 2.65-2.53(\mathrm{~m}$, $\left.1 \mathrm{H}, \mathrm{CH}_{2} \mathrm{CH}_{b} \mathrm{CH}_{2} \mathrm{OH}\right), 2.47-2.34\left(\mathrm{~m}, 1 \mathrm{H}, \mathrm{CH}_{a} \mathrm{CH}_{\mathrm{b}} \mathrm{CH}_{2} \mathrm{OH}\right), 2.05(\mathrm{~s}, 3 \mathrm{H}$, $\left.\mathrm{CH}_{3}\right), 1.96\left(\mathrm{~s}, 3 \mathrm{H}, \mathrm{CH}_{3}\right) .{ }^{13} \mathrm{C}\left\{{ }^{1} \mathrm{H}\right\} \mathrm{NMR}(75 \mathrm{MHz}, \mathrm{DMSO}, \delta): 104.1,102.7$,
95.7, 87.5, 87.2, 83.3, 60.4, 36.2, 17.0, 16.3. IR: $v_{\max } \mathrm{cm}^{-1} 735,863,899$, 1023, 1044, 1081, 117, 1211, 1297, 1377, 1438, 2858, 2914, 3039, 3429 (br). HRMS (ESI) calculated for $\mathrm{C}_{12} \mathrm{H}_{17} \mathrm{O}_{3} \mathrm{Ru}\left[\mathrm{Ru}(\text { arene)OAc] }]^{+}\right.$: 311.0220 , Found: 311.0217

Synthesis of $\left[\mathrm{RuCl}_{2} \quad \mathrm{O}\right.$-(3,4-dimethylphenethyl $\mathrm{N}$-(3(triethoxysilyl)propyl) carbamate) $]_{2}$ (5). In a modification of a previously reported literature procedure,[24a] 3-(triethoxysilyl)propyl isocyanate $(0.26$ $\mathrm{mL}, 1.1 \mathrm{mmol})$ was added to $\left[\mathrm{RuCl}_{2} \text { (2-(3,4-dimethylphenyl)ethan-1-ol) }\right]_{2}$ $(0.456 \mathrm{~g}, 0.70 \mathrm{mmol})$ and $\mathrm{NEt}_{3}(0.49 \mathrm{~mL}, 3.54 \mathrm{mmol})$ in dry dichloromethane $(10 \mathrm{~mL})$. The reaction mixture was heated to $38^{\circ} \mathrm{C}$ for 48 $\mathrm{h}$. The solvent was removed under reduced pressure to obtain a brown oil which was triturated with hexane $(2 \times 10 \mathrm{~mL})$. The resulting crude oil $(0.645$ $\mathrm{g}, 77 \%)$ was re-dissolved in dry dichloromethane $(10 \mathrm{~mL})$ to give a dark red solution which was used without further purification. ${ }^{1} \mathrm{H} N \mathrm{NMR}(300 \mathrm{MHz}$, $\left.\mathrm{CDCl}_{3}, \delta\right): 5.28-4.82(\mathrm{~m}, 3 \mathrm{H}, \mathrm{Ar}-\underline{\mathrm{H}})$, 4.38-4.11 (m, $\left.2 \mathrm{H}, \mathrm{CH}_{2} \mathrm{C}_{2} \mathrm{O}\right)$, 3.84$3.64\left(\mathrm{~m}, 6 \mathrm{H},\left(\mathrm{CH}_{3} \mathrm{CH}_{2} \mathrm{O}\right)_{3} \mathrm{Si}\right), 3.15-2.97\left(\mathrm{~m}, 2 \mathrm{H}, \mathrm{CH}_{2} \mathrm{NH}\right)$ 2.90-2.69 (m, $2 \mathrm{H}$, $\left.\mathrm{C}_{6} \mathrm{H}_{3}-\mathrm{CH}_{2} \mathrm{CH}_{2} \mathrm{O}\right)$, 2.19-2.06 (m, 3H, $\left.\mathrm{CH}_{3}\right), 2.07-1.99\left(\mathrm{~m}, 3 \mathrm{H}, \mathrm{CH}_{3}\right)$ 1.62$1.43\left(\mathrm{~m}, 2 \mathrm{H}, \mathrm{NHCH}_{2} \mathrm{CH}_{2} \mathrm{CH}_{2}\right), 1.21-1.07\left(\mathrm{~m}, 9 \mathrm{H},\left(\mathrm{CH}_{3} \mathrm{CH}_{2} \mathrm{O}\right) 3 \mathrm{Si}\right), 0.60$ $0.43\left(\mathrm{~m}, 6 \mathrm{H}, \mathrm{CH}_{2} \mathrm{Si}\right)$. IR: $v_{\max } \mathrm{cm}^{-1} 3264,2973,2927,2882,1682,1254$, 1069, 951, 768. HRMS (ESI) calculated for $\mathrm{C}_{20} \mathrm{H}_{35} \mathrm{O}_{5} \mathrm{NCIRuSi}$, [Ru(arene)Cl]+: 534.1011, found: 534.1011.

Synthesis of Silica-Supported Ruthenium Dimers 6 and 7. A twonecked flame-dried round bottom flask was charged with $5(4.88 \% \mathrm{w} / \mathrm{w}$ solution in dichloromethane; $6 \mathrm{~mL}$, containing $0.34 \mathrm{mmol}$ of $\mathrm{Ru}$ ), the solvent was removed under reduced pressure and toluene $(6 \mathrm{~mL})$ added. Amorphous silica or DAVISIL $(7.10 \mathrm{~g})$ was then added to the solution and the mixture was heated to $110^{\circ} \mathrm{C}$ with rapid stirring for $24 \mathrm{~h}$. After this time the mixture was left to cool and the solid was filtered, washed with ethy acetate $(3 \times 10 \mathrm{~mL})$ and dried at $45^{\circ} \mathrm{C}$ overnight to afford 6 and 7 as orange solids in $93 \%(7.45 \mathrm{~g})$ and $99 \%(7.49 \mathrm{~g})$ yield, respectively. ICP-OES data for 6: $0.23 \mathrm{wt} \%$ ruthenium corresponding to a ruthenium loading of 0.023 mmol g-1 ICP-OES data for 7: $0.37 \mathrm{wt} \%$ ruthenium corresponding to a ruthenium loading of $0.037 \mathrm{mmol} \mathrm{g}^{-1}$.

Synthesis of Silica-Supported [\{2-(3,4-Dimethylphenylethyl propyl carbamate)\}Ru\{(S,S)-T-DPEN)Cl] Precatalysts 8 and 9. In a typical procedure, triethylamine $(0.094 \mathrm{~mL}, 0.68 \mathrm{mmol})$, silica-supported ruthenium dimer 6 or 7 (mass corresponding to $0.34 \mathrm{mmol}$ of Ru calculated from the ruthenium loading) and (S,S)-TsDPEN $(0.155 \mathrm{~g}, 0.42 \mathrm{mmol})$ were stirred in dichloromethane $(20 \mathrm{~mL})$ for $4 \mathrm{~h}$ at room temperature after which time the solid was filtered, washed with dichloromethane $(3 \times 5 \mathrm{~mL})$ and dried in an oven at $40^{\circ} \mathrm{C}$ for $5 \mathrm{~h}$ to obtain silica-supported precatalysts 8 and 9 as orange solids in $99 \%(3.7 \mathrm{~g})$ and $98 \%(3.7 \mathrm{~g})$ yield, respectively. ICP-OES data for 8: 0.21 wt \% ruthenium corresponding to a ruthenium loading of $0.021 \mathrm{mmol} \mathrm{g}^{-1}$. ICP-OES data for 9: $0.32 \mathrm{wt} \%$ ruthenium corresponding to a ruthenium loading of $0.032 \mathrm{mmol} \mathrm{g}^{-1}$.

Synthesis of RuCI(S,S)-TSDPEN[(2-(3,4-dimethylphenyl)ethan-1-ol] (10). In a modification of a previously reported literature procedure, ${ }^{[24 a]}$ $(S, S)$-TSDPEN $(0.100 \mathrm{~g}, 0.28 \mathrm{mmol}), 4(0.089 \mathrm{~g}, 0.14 \mathrm{mmol})$ and triethylamine $(0.056 \mathrm{~g}, 0.55 \mathrm{mmol})$ were dissolved in dichloromethane (3 $\mathrm{mL}$ ) and the reaction mixture was stirred at room temperature for $1 \mathrm{~h}$. The resulting orange solid was filtered, washed with dichloromethane $(1 \mathrm{~mL})$ and dried to obtain precatalyst 10 as an orange solid $(0.103 \mathrm{~g}, 56 \%) .{ }^{1} \mathrm{H}$

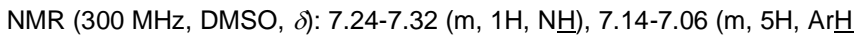
$+\mathrm{NH}), 6.83-6.54(\mathrm{~m}, 1 \mathrm{OH}, \mathrm{Ar} \underline{\mathrm{H}}), 5.74(\mathrm{~s}, 1 \mathrm{H}, \mathrm{Ar} \underline{\mathrm{H}}), 5.62-5.59(\mathrm{~m}, 1 \mathrm{H}, \mathrm{Ar} \underline{\mathrm{H}})$, 5.44-5.43 (m, $1 \mathrm{H}, \mathrm{Ar} \underline{\mathrm{H}}), 4.91-4.89(\mathrm{~m}, 1 \mathrm{H}, \mathrm{OH}), 3.80-3.75\left(\mathrm{~m}, 2 \mathrm{H}, \mathrm{C}_{2} \mathrm{OH}\right)$, 3.62-3.60 (m, 1H, CHNTs), 3.16-3.10 (m, $1 \mathrm{H}, \mathrm{CHN}), 2.92-2.86(\mathrm{~m}, 1 \mathrm{H}$, $\left.\mathrm{CH}_{a} \mathrm{H}_{b} \mathrm{CH}_{2} \mathrm{OH}\right), 2.69-2.64\left(\mathrm{~m}, 1 \mathrm{H}, \mathrm{CH}_{a} \underline{H}_{b} \mathrm{CH}_{2} \mathrm{OH}\right), 2.22$ (s, 3H, Me), 2.20 (s, 3H, Me), $2.08(\mathrm{~m}, 3 \mathrm{H}, \mathrm{Me}) .{ }^{13} \mathrm{C}\left\{{ }^{1} \mathrm{H}\right\}$ NMR $(75 \mathrm{MHz}, \mathrm{DMSO}, \delta): 143.7$, $140.5,140.2,138.6,129.3,128.5,127.9,127.9,127.5,127.5,127.1,126.4$, 94.6, 94.4, 94.3, 88.7, 81.2, 79.4, 71.9, 69.3, 61.3, 36.7, 21.2, 17.1, 16.9.

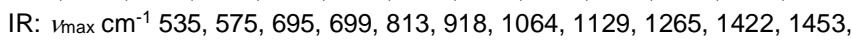
$1575,2875,2925,3028,3056,3243,3301,3433$ (br). HRMS (ESI) calculated for $\mathrm{C}_{31} \mathrm{H}_{35} \mathrm{~N}_{2} \mathrm{O}_{3}$ RuS [M-Cl] ${ }^{+}$: 611.1439; found: 611.1440. M.P.: $221-223{ }^{\circ} \mathrm{C}$. 
ATH of Acetophenone and its Derivatives Using Preformed SilicaSupported Precatalysts 8 and 9 . Ketone $(0.5 \mathrm{mmol})$ was added to a suspension of either $8(0.22 \mathrm{~mol}-\% \mathrm{Ru}, 0.052 \mathrm{~g}, 0.0011 \mathrm{mmol})$ or $9(0.34$ $\mathrm{mol}-\% \mathrm{Ru}, 0.053 \mathrm{~g}, 0.0017 \mathrm{mmol}$ ) and $5: 2$ formic acid:triethylamine azeotrope $\left(0.25 \mathrm{~mL}, 3.0 \mathrm{mmol}\right.$ of $\left.\mathrm{HCO}_{2} \mathrm{H}\right)$ in a flame-dried Schlenk tube and the mixture stirred at the specified temperature for the allocated time. The orange mixture was filtered through a short silica plug, washed through with diethyl ether $(2 \times 10 \mathrm{~mL})$ and the solvent removed under reduced pressure. The residue was dissolved in $\mathrm{CDCl}_{3}(0.7 \mathrm{~mL})$, decane $(97 \mu \mathrm{L}, 0.5 \mathrm{mmol}$ ) added as internal standard, and the solution analysed by ${ }^{1} \mathrm{H}$ NMR spectroscopy and gas chromatography to determine the conversion and enantioselectivity.

ATH of Acetophenone Using In-Situ Generated Silica-Supported Precatalysts. A flame-dried Schlenk flask was charged with silicasupported ruthenium dimer $6(0.22 \mathrm{~mol}-\%, 0.048 \mathrm{~g}, 0.0011 \mathrm{mmol})$ or 7 $(0.34 \mathrm{~mol}-\%, 0.046 \mathrm{~g}, 0.0017 \mathrm{mmol})$, ligand (1.3 equivalents based on ruthenium) and triethylamine (2.0 equivalents based on ruthenium) and the resulting suspension stirred for $1 \mathrm{~h}$ under nitrogen at $55^{\circ} \mathrm{C}$. After this time, $\mathrm{HCO}_{2} \mathrm{H} / \mathrm{NEt}_{3}\left(0.25 \mathrm{~mL}, 3.0 \mathrm{mmol}\right.$ of $\left.\mathrm{HCO}_{2} \mathrm{H}\right)$ and the ketone $(0.5 \mathrm{mmol})$ were added and the mixture stirred at $55{ }^{\circ} \mathrm{C}$ for the allocated time, after which it was filtered through silica and washed through with diethyl ether $(2 \times 10 \mathrm{~mL})$ and the solvent removed under reduced pressure. The residue was dissolved in $\mathrm{CDCl}_{3}(0.7 \mathrm{~mL})$, decane $(97 \mu \mathrm{L}, 0.5 \mathrm{mmol})$ was added as internal standard and the solution analysed by ${ }^{1} \mathrm{H}$ NMR spectroscopy and gas chromatography to determine the conversion and enantioselectivity.

ATH of Acetophenone and its Derivatives Using Precatalyst 10. A flame-dried Schlenk flask containing 5:2 formic acid:triethylamine $(0.25 \mathrm{~mL}$ $3.0 \mathrm{mmol}$ of $\left.\mathrm{HCO}_{2} \mathrm{H}\right)$ and the ketone $(0.5 \mathrm{mmol})$ was charged with precatalyst $10(0.0036 \mathrm{~g}, 5.5 \mu \mathrm{mol}, 1 \mathrm{~mol} \%)$ and the resulting mixture stirred at $50^{\circ} \mathrm{C}$ for $5 \mathrm{~h}$. After this time, the resulting orange mixture was filtered through silica and flushed with diethyl ether $(2 \times 10 \mathrm{~mL})$ and the solvent removed under reduced pressure. The residue was dissolved in $\mathrm{CDCl}_{3}(0.7 \mathrm{~mL})$ and decane $(97 \mu \mathrm{L}, 0.5 \mathrm{mmol})$ added as internal standard and the solution analysed by ${ }^{1} \mathrm{H}$ NMR spectroscopy and gas chromatography to determine the conversion and enantioselectivity.

ATH of Acetophenone Using Precatalyst 10 Generated In-Situ from 4. A Schlenk flask was charged with $5: 2$ formic acid:triethylamine $(0.25 \mathrm{~mL}$, $3.0 \mathrm{mmol}$ of $\left.\mathrm{HCO}_{2} \mathrm{H}\right), 4(0.0035 \mathrm{~g}, 5.0 \mu \mathrm{mol})$ and $(S, S)-T s D P E N(2.8 \mathrm{mg}$ $7.6 \mu \mathrm{mol}$ ) and the mixture stirred at $55^{\circ} \mathrm{C}$ for $15 \mathrm{~min}$. After this time, acetophenone $(0.058 \mathrm{~mL}, 0.50 \mathrm{mmol})$ was added and stirring continued for a further $90 \mathrm{~min}$. The resulting orange mixture was filtered through silica and flushed through with diethyl ether $(2 \times 10 \mathrm{~mL})$ and the solvent removed under reduced pressure. The residue was dissolved in $\mathrm{CDCl}_{3}(0.7 \mathrm{~mL})$, decane ( $97 \mu \mathrm{L}, 0.5 \mathrm{mmol}$ ) was added as internal and the solution analysed by ${ }^{1} \mathrm{H}$ NMR spectroscopy and gas chromatography to determine the conversion and enantioselectivity.

General Procedure for Catalyst Recycling. A centrifuge tube was charged with precatalyst $9(0.17 \mathrm{~mol} \%, 0.106 \mathrm{~g}, 0.0034 \mathrm{mmol}), 5: 2$ formic acid:triethylamine $\left(1.0 \mathrm{~mL}, 12.0 \mathrm{mmol}\right.$ of $\left.\mathrm{HCO}_{2} \mathrm{H}\right)$ and acetophenone $(0.232 \mathrm{~mL}, 0.2 \mathrm{mmol})$ and the reaction mixture heated at $55{ }^{\circ} \mathrm{C}$ for $5 \mathrm{~h}$ under a nitrogen atmosphere. After this time water was added $(1.0 \mathrm{ml})$ and the tube was placed in a centrifuge at $5000 \mathrm{rpm}$ for $5 \mathrm{~min}$ and the formic acid:triethylamine carefully removed by pipette. Following this the solid was re-suspended in formic acid:triethylamine azeotrope and water, centrifugation repeated and the formic acid:triethylamine removed. After a third washing the solid was dried in vacuum before adding further portions of formic acid:triethylamine azeotrope and acetophenone. The combined aqueous washings were extracted with diethyl ether to obtain a sample for analysis by ${ }^{1} \mathrm{H}$ NMR spectroscopy and gas chromatography.
Crystal structure data were collected at $150 \mathrm{~K}$ on a Rigaku Oxford Diffraction Xcalibur, Altas, Gemini Ultra diffractometer using equipped with a sealed tube $\mathrm{X}$-ray source $\left(\lambda_{\text {cuka }}=1.54184 \AA\right)$ and an Oxford CryostreamPlus open-flow $\mathrm{N}_{2}$ cooling device. Intensities were corrected for absorption using a multifaceted crystal model created by indexing the faces of the crystal for which data were collected. ${ }^{[38]}$ Cell refinement, data collection and data reduction were undertaken via the software CrysAlisPro. ${ }^{[39]}$ All structures were solved using $\mathrm{XT}^{[40]}$ and refined by $\mathrm{XL}^{[41]}$ using the Olex2 interface. ${ }^{[42]}$ All non-hydrogen atoms were refined as anisotropic and hydrogen atoms were positioned with idealised geometry, with the exception of those bound to heteroatoms, the positions of which were located using peaks in the Fourier difference map. The displacement parameters of the hydrogen atoms were constrained using a riding model with UH set to be an appropriate multiple of the Ueq value of the parent atom.

Deposition Numbers 2045014 (for 4) and 2045015 (for 10) contain the supplementary crystallographic data for this paper. These data are provided free of charge by the joint Cambridge Crystallographic Data Centre and Fachinformationszentrum Karlsruhe Access Structures service www.ccdc.cam.ac.uk/structure

\section{Acknowledgements}

We gratefully acknowledge the Deanship of Scientific Research (DSR) at King Abdulaziz University, Jeddah, Saudi Arabia for funding this project (grant no: KEP-37-130-41). High-resolution mass spectra were obtained at the EPSRC National Mass Spectrometry Service in Swansea. We also thank Dr Kathryn White for the SEM images (Faculty of Medical Sciences, Newcastle University).

Keywords: arene-immobilised • silica • (arene)Ru(II)/TsDPEN • asymmetric hydrogenation $\bullet$ ketones

[1] a) M. J. Palmer, M. Wills, Tetrahedron: Asymmetry 1999, 10, 2045-2061 b) X. Wu, J. Xiao, Chem. Commun. 2007, 24, 2449-2466; c) H.-U. Blaser, C. Malan, B. Pugin, F. Spindler, H. Steiner, M. Studer, Adv. Synth. Catal. 2003, 345, 103-151; d) K. Everaere, A. Mortreux, J.-F. Carpentier, Adv. Synth. Catal. 2003, 345, 67-77; e) C. Saluzzo, M. Lemaire, Adv. Synth. Catal. 2002, 344, 915-928; f) Q.-H. Fan, Y.-M. Li, A. S. C. Chan, Chem. Rev. 2002, 102, 3385-3466.

[2] a) S. Hashiguchi, A. Fujii, J. Takehara, T. Ikariya, R. Noyori, J. Am. Chem. Soc. 1995, 117, 7562-7563; b) A. Fujii, S. Hashiguchi, N. Uematsu, T. Ikariya, R. Noyori, J. Am. Chem. Soc. 1996, 118, 2521-2522; c) K. Matsumura, S. Hashiguchi, T. Ikariya, R. Noyori, J. Am. Chem. Soc. 1997, 119, 8738-8739; d) K. Murata, K. Okano, M. Miyagi, H. Iwane, R. Noyori, T. Ikariya, Org. Lett. 1999, 1, 1119-1121.

[3] a) Y.-M. He, Q.-H. Fan, Org. Biomol. Chem. 2010, 8, 2497-2504; b) T. Touge, T, Arai, J. Am. Chem. Soc. 2016, 138, 11299-13105; c) T. Ohkuma, N. Utsumi, K. Tsutsumi, K. Murata, C. Sandoval, R. Noyori, J. Am. Chem. Soc. 2006, 128, 8724-8725; d) W. Ma, J. Zhang, C. Xu, F. Chen, Y.-M. He, Q.-H. Fa, Angew. Chem. Int. Ed. 2016, 55, 1289112894; e) C. A. Sandoval, T. Ohkuma, N. Utsumi, K. Tsutsumi, K. Murara, R. Noyori, Chem.-Asian J. 2006, 1, 102-110; f) Z. Yang, F. Chen, Y. He, N. Yang, Q.-H. Fa, Angew. Chem. Int. Ed. 2016, 55, 13863-13866; g) T. Ohkuma, K. Tsutsumi, N. Utsumi, N. Arai, R. Noyori, K. Murata, Org. Lett., 2007, 9, 255-257; h) M. Ito, Y. Endo, T. Ikariya, Organometallics 2008, 27, 6053-6055; i) Z. M. Heiden, T. B. Rauchfuss, J. Am. Chem. Soc. 2009, 131, 3593-3600.

[4] For a highly informative and insightful review see: a) H. G. Nedden. A. Zanotti-Gerosa, M. Wills, Chem. Rec. 2016, 16, 2623-2643; For selected examples see: b) D. J. Cross, J. A. Kenny, I. Houson, L. Campbell, T. 
Walsgrove, M. Wills, Tetrahedron: Asymmetry 2001, 12, 1801-1806; c) F. K. Cheung, C. Lin, F. Minissi, A. L. Crivillé, M. A. Graham, D. J. Fox M. Wills, Org. Lett. 2007, 9, 4659-4662; d) J. Wettergren, E. Buitrago, P. Ryberg, H. Adolfsson, Chem.-Eur. J, 2009, 15, 5709-5718; e) A. E. Cotman, D. Cahard, B. Mohar, Angew. Chem. Int. Ed. 2016, 55, 5294 5298; f) A. Kišić, M. Stephan, B. Mohar, Adv. Synth. Catal. 2015, 357 2540-2546; g) T. Thorpe, A. J. Blacker, S. M. Brown, C. Bubert, J. Crosby, S. Fitzjohn, J. P. Muxworthy, J. M. J. Williams, Tetrahedron Lett. 2001, 42, 4041-4043; h) A. Schlatter, W.-D. Woggon, Adv. Synth. Catal, 2008, 350, 995-1000; i) W. Baratta, F. Benedetti, A. Del Zotto, L. Fanfoni, F. Felluga, S. Magnolia, E. Putignano, P. Rigo, Organometallics 2010, 29, 3563-3570; j) X. Wu, J. Xiao, Chem. Commun. 2007, 2449-2466; k) D. Šterk, M. S. Stephan, B. Mohar, Tetrahedron: Asymmetry 2002, 13 2605-2608; I) R. Soni, K. E. Jolley, G. J. Clarkson, M. Wills, Org. Lett. 2013, 15, 5110-5113; m) V. Parekh, J. A. Ramsden, M. Wills, Catal. Sci. Technol. 2012, 2, 406-414.

[5] a) P. A. Bradley, R. L. Carroll, Y. C. Lecouturier, R. Moore, P. Noeureuil, B. Patel, J. Snow, S. Wheeler, Org. Process Res. Dev. 2010, 14, 13261336; b) R. Fu, J. Chen, L.-C. Guo, J.-L. Ye, Y.-P. Ruan, P.-Q. Huang Org. Lett. 2009, 11, 5242-5245; c) G. Kumarasway, G. Ramakrishna, P. Naresh, B. Jagadeesh, B. Sridhar, J. Org. Chem. 2009, 74, 8468-8471 d) T. J. Greshock, D. M. Johns, Y. Noguchi, R. M. Williams, Org. Lett. 2008, 10, 613-616; e) Q. Zhang, B.-W. Ma, Q.-Q. Wang, X.-X. Wang, X Hu, M.-S. Xie, G.-R. Qu, H.-M. Guo, Org. Lett. 2014, 16, 2014-2017; f) M. Hennig, K. Püntener. M. Scalone, Tetrahedron: Asymmetry 2000, 11 1849-1858; g) Z. Ding, J. Yang, T. Wang, Z. Shen, Y. Zhang, Chem. Commun. 2009, 571-573; h) B. Zhang, M.-H. Xu, G.-Q. Lin, Org. Lett. 2009, 11, 4712-4715; i) G. Kumaraswamy, D. Rambabu, Tetrahedron Asymmetry 2013, 24, 196-201; j) K. Leijondahl, A.-B. L. Fransson, J.-E. Bäckvall, J. Org. Chem. 2006, 71, 8622-8625; k) N. J. Alcock, I. Mann, P. Peach, M. Wills, Tetrahedron: Asymmetry 2002, 13, 2485-2490; I) I. C. Lennon, J. A. Ramsden, Org. Process Res. Dev. 2005, 9, 110-112; m) T. Kioke, K. Murata, T. Ikariya, Org. Lett. 2000, 2, 3833-3836.

[6] For relevant reviews see: a) J. Barrios-Rivera, Y. Xu, M. Wills, Org. Biomol. Chem. 2019, 7, 1301-1321; b) F. Foubelo, C. Nájera, M. Yu, Tetrahedron: Asymmetry 2015, 26, 769-790; c) A. Zoabi, S. Omar, R. Abu-Reziq, Eur. J. Org. Chem., 2015, 2101-2109; d) J. G. Deng, Y. Q. Tu, S. H. Wang, Chem. Commun. 2004, 2070-2071; e) P. N. Liu, P. M. Gu, J. G. Deng, Y. Q. Tu, Y. P. Ma, Eur. J Org. Chem. 2005, 3221-3227; f) R. N. Liu, P. M. Gu, F. Wang, Y. Q. Tu, Org. Lett. 2004, 6, 169-172; g) R. Liu, T. Cheng, L. Kong, C. Chen, G. Liu, H. Li, J. Catal. 2013, 307, 55-61; h) J. Li, Y. Zhang, D. Han, Q. Gao, C. Li, J. Mol. Cat. A: Chemical 2009, 298, 31-35; i) X. Huang, J. Y. Ying, Chem. Commun. 2007, 18251827; j) D. Zhang, J. Xu, Q. Zhao, T. Cheng, G. Liu, ChemCatChem 2014 6, 2998-3003.

[7] a) R. Wang, J. Wan, X. a, X. Xu, L. Liu, J. Chem Soc. Dalton Trans. 2013, 42, 6513-6522; b) X. Xu, R. Wang, J. Wan, X. Ma, J. Peng, RSC Adv. 2013, 3, 6747-6751; c) N. Haraguchi, K. Tsuru, Y. Arakawa, S. Itsuno Org. Biomol. Chem. 2009, 7, 69-75; d) R. Marcos, C. Jimeno, M. A Perciàs, Adv. Synth. Catal. 2011, 353, 1345-1352; e) R. Akiyama, S Kobayashi, Angew Chem. Int Ed. 2002, 41, 2602-2604; f) Y. Arakawa, A. Chiba, N. Haraguchi, S. Itsuno, Adv. Synth Catal. 2008, 350, 22952304; g) C. M. Zammit, M. Wills, Tetrahedron: Asymmetry 2013, 24, 844 852.

[8] a) W. Shan, F. Meng, Y. Wu, F. Mao, X. Li. J. Organomet. Chem. 2011, 696, 1687-1690; b) J. Liu, Y. Zhou, Y. Wu, X. Li, A. S. C. Chan, Tetrahedron: Asymmetry 2008, 19, 832-837; c) H. F. Zhou, Q. H. Fan, Y. Y. Huang, L. Wu, Y. M. He, W. J. Tang, L. Q. Gu, A. S. C. Chan, J Mol. Cat. A: Chemical 2007, 275, 47-53; d) Y. Wu, C. Lu, W. Shan, X. Li, Tetrahedron: Asymmetry 2009, 20, 584-587.

[9] a) X. Li, X. Wu, W. Chen, F. E. Hancock, F. King. J. Xiao, Org. Lett. 2004 6, 3321-3324; b) X. Li, W. Hems, F. King, J. Xiao, Tetrahedron Lett. 2004 45, 951-953.

[10] J. M. Zimbron, M. Dauphinais, A. B. Charette, Green Chem. 2015, 17, 3255-3259.

[11] a) I. Kawasaki, K. Tsunoda, T. Tsuji, T. Yamaguchi, H. Shibuta, N. Uchida, M. Yamashita, S. Ohta, Chem. Commun. 2005, 2134-2135; b) T. J. Geldbach, P. J. Dyson, J. Am. Chem. Soc. 2004, 126, 8114-8115.
[12] a) Y. C. Chen, T. F. Wu, L. Jiang, J. G. Deng, H. Liu, J. Zhu, Y. Z. Jiang J. Org. Chem. 2005, 70, 1006-1010; b) W. Liu, X. Cui, L. Cun, J. Zhu, J. Deng, Tetrahedron: Asymmetry 2005, 16, 2525-2530.

[13] a) Y. Zhao, R. Jin, Y. Chan, Y. Li, J. Lin, G. Liu, RSC Adv. 2017, 7, 22592-22598; b) G. Zhang, T. Liu, Y. Chou, Y. Wang, T. Cheng, G. Liu, ChemCatChem 2018, 10, 1882-1888; c) M. Gao, F. Chang, S. Wang, Z. Liu, Z. Zhao, G. Liu, J. Catal. 2019, 370, 191-197; d) J. Meng, F. Chang, Y. Su, R. Liu, T. Cheng, G. Liu, ACS Catal. 2019, 9, 8693-8701.

[14] S. B. Wendicke, E. Burris, R. Scopelliti, K. Severin, Organometallics 2003, 22, 1894-1897.

[15] T. Cheng, Q. Zhao, D. Zhang, G. Liu, Green Chem. 2015, 17, $2100-$ 2122

[16] S. H. Yang, S. Chang, Org. Lett. 2001, 3, 2089-2091.

[17] Y. Na, S. Chang, Org. Lett. 2000, 2, 1887-1889.

[18] P. J. Dyson, D. J. Ellis, T. Welton, J. Am. Chem. Soc. 2002, 124, 93349335.

[19] a) U. Karlsson, G.-Z. Wang, J.-E. Bäckvall, J. Org. Chem. 1994, 59, 1196-1198; b) M. Lee, S. Chang, Tetrahedron Lett. 2000, 41, 7507-7510.

[20 a) D. L. Davies, J. Fawcett, S. A. Garratt, D. R. Russell, Organometallics 2001, 20, 3029-3034; b) J. W. Faller, B. J. Grimmond, Organometallics 2001, 20, 2454-2458; c) D. L. Davies, J. Fawcett, S. A. Garratt, D. A. Russell, Chem. Commun. 1997, 1352-1352.

[21] a) F. Simal, A. Demonceau, A. F. Noels, Tetrahedron Lett. 1998, 39, 3493-3496. (b) F. Simal, D. Jan, A. Demonceau, A. F. Noels, Tetrahedron Lett. 1999, 40, 1653-1656.

[22] S. Doherty, C. R. Newman, R. K. Rath, M. Nieuwenhuyzen, J. G. Knight, W. Clegg Organometallics 2005, 24, 2633-2644.

[23] For ring closing metathesis see: a) E. L. Dias, R. H. Grubbs, Organometallics 1998, 17, 2758-2767; b) A. Fürstner, M. Picquet, C Bruneau, P. H. Dixneuf, Chem. Commun. 1998, 1315-1316; c) A. Fürstner, M. Liebl, C. W. Lehmann, M. Picquet, R. Kunz, C. Bruneau, D. Touchard, P. H. Dixneuf, Chem. Eur. J. 2000, 6, 1847-1857; d) A. Fürstner, L. Ackermann, Chem. Commun. 1999, 95-96. For ring-opening metathesis see: e) A. Hafner, A. Mühlebach, P. A. van der Schaaf, Angew. Chem. Int. Ed. Engl. 1997, 36, 2121-2124; f) A. Demonceau, A W. Stumpf, E. Saive, A. F. Noels, Macromolecules 1997, 30, 3127-3136; g) A. W. Stumpf, E. Saive, A. Demonceau, A. F. Noels, J. Chem. Soc., Chem. Commun. 1995, 1127-1128.

[24] a) T. Touge, T. Hakamata, H. Nara, T. Kobayashi, N. Sayo, T. Saito, Y. Kayaki, T. Ikariya, J. Am. Chem. Soc. 2011, 133, 14960-14963; b) P. Mörschel, J. Janikowski, G. Hilt, G. Frenking, J. Am. Chem Soc. 2008, 130, 8952-8966.

[25] T. Meng, Q.-P. Qin, Z.-L. Chen, H.-H. Zou, K. Wang, F.-P. Liang, Dalton Trans. 2019, 48, 5352-5360.

[26] J. Soleimannejad, C. White, Organometallics 2005, 24, 2538-2541.

[27] B. Therrien, G. Süss-Fink, Inorg. Chim. Acta 2006, 359, 4350-4354.

[28] F. Martínez-Peña, S. Infante-Tadeo, A. Habtemariam, A. M. Pizarro, Inorg. Chem. 2018, 57, 5657-5668.

[29] a) K.-J. Haack, S. Hashiguchi, A. Fujii, T. Ikariya, R. Noyori, Angew Chem. Int. Ed. 1997, 36, 285-288; b) N. Uematsu, A. Fujii, S. Hashiguchi, T. Ikariya, R. Noyori, J. Am. Chem. Soc. 1996, 118, 4916-4917.

[30] B. Vilhanová, J. Václavík, P. Šot, J. Pecháček, J. Zápal, R. Pažout, J. Maixner, M. Kuzma, P. Kačer, Chem Commun. 2016, 52, 362-365.

[31] J. Soleimannejad, A. Sisson, C. White, Inorg. Chim. Acta 2003, 352, 121-128.

[32] a) S. Bai, H. Yang, P. Wang, J. Gao, B. Li, Q. Yang, C. Li, Chem. Commun. 2010, 46, 8145-8147; b) H. Yang, J. Li, J. Yang, Z. Liu, Q. Yang, C. Li, Chem. Commun. 2007, 1086-1088.

[33] a) J. M. Thomas, T. Maschmeyer, B. F. G. Johnson, D. S. Shepard, J. Mol. Cat. A: Chem. 1999, 141, 139-144; b) F. Goettmanna, C. Sanchez, J. Mater. Chem. 2007,17, 24-30; c) V. Mouarrawis, R. Plessius, J. I. van der Vlugt, J. N. H. Reek, Frontiers in Chem. 2018, 6, 623.

[34] B. Pugin, J. Mol. Cat. A: Chem. 1996, 107, 273-279.

[35] a) M. Yamakawa, I. Yamada, R. Noyori, Angew. Chem. Int. Ed. 2001, 40, 2818-2821; b) D. J. Morris, A. M. Hayes, M. Wills, J. Org. Chem. 2006 71, 7035-7044.

[36] A. M. R. Hall, P. Dong, A. Codina, J. P. Lowe, U. Hintermair, ACS Catal. 2019, 9, 2079-2090. 
FULL PAPER

[37] L. Vieille-Petit, B. Therrien, G. Süss-Fink, Eur. J. Inorg. Chem. 2003, 20, 3707-3711.

[38] R. C. Clark, J. S. Reid, Acta Cryst. 1995, A51, 887-897.

[39] CrysAlisPro, Rigaku Oxford Diffraction, Tokyo, Japan.

[40] G. M. Sheldrick, Acta Cryst. 2015, A71, 3-8.

[41] G. M. Sheldrick, Acta Cryst. 2008, A64, 112-122.

[42] O. V. Dolomanov, L. J. Bourhis, R. J. Gildea, J. A. K. Howard, H. Puschmann, J. Appl. Cryst. 2009, 42, 339-341. 
FULL PAPER

\section{Entry for the Table of Contents}

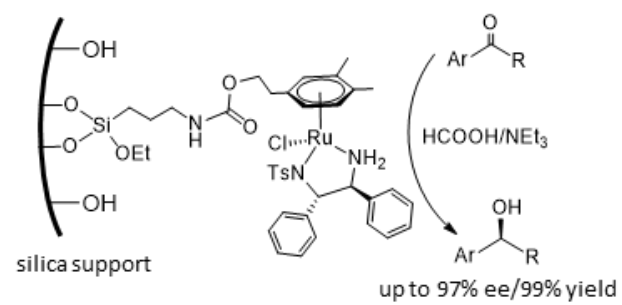

Key Topic Asymmetric Transfer Hydrogenation

Herein we report the first examples of (arene) Ru(II)/TsDPEN anchored to silica through the coordinated $\eta^{6}$-arene ligand and their application to the asymmetric transfer hydrogenation of ketones. The initial TOFs (up to $1085 \mathrm{~h}^{-1}$ ) and ee's (96-97\%) obtained with these catalysts either rivalled or outperformed those obtained with their homogeneous counterparts as well as systems immobilized on silica, a polymer or PEG through one of the nitrogen atoms of TsDPEN. 